\title{
NEGATIVE EFFECTS OF DESIGN-BID-BUILD PROCUREMENT ON CONSTRUCTION PROJECTS
}

\author{
Sergei Kortenko ${ }^{1}$, Lauri Koskela ${ }^{2}$, \\ Patricia Tzortzopoulos $^{3}$, and Shervin Haghsheno ${ }^{4}$
}

\begin{abstract}
The construction industry is famous for its poor performance. Despite multi-party contractual agreements acknowledged by the lean construction community as enablers of better communication and performance, design-bid-build (DBB) still dominates the construction industry in Germany, UK and other countries. This study describes designbid-build procurement and explores its negative effects on construction projects, environment and project participants through a review of existing literature. Understanding the influence of design-bid-build on construction environment should give practitioners an insight into the potential of using the Last Planner ${ }^{\circledR}$ System and other lean tools. The direct and indirect effects of DBB on the construction environment are presented in the form of a tree diagram. It can be hypothesized that if the internal dispositions of project participants can be determined and the behavior of project participants can be positively influenced, for example, by lean management tools such as the Last Planner ${ }^{\circledR}$ System $^{5}$, the situational context in which project participants operate can be influenced too, meaning a shift to more positive, collaborative environment.
\end{abstract}

\section{KEYWORDS}

Contract, transactional, design-bid-build, cost-led procurement, collaboration.

\section{INTRODUCTION}

The construction industry is often criticized for its poor performance (e.g., Mahamid 2016). The Lean construction community tries to find possible ways of improving the industry through multi-party contractual arrangements of project partnering, project alliancing and integrated project delivery (Hamzeh et al. 2019). However, traditional

1 Researcher, School of Art, Design and Architecture, University of Huddersfield, Drees \& Sommer, Frankfurt am Main, Germany, +491727698610, sergei.kortenko@hud.ac.uk, kortenko86@gmail.com, orcid.org/0000-0003-0968-2100

2 Professor of Construction/Project Management, School of Art, Design and Architecture, University of Huddersfield, Queensgate, Huddersfield, HD1 3DH, UK, +441484472892,1.koskela@hud.ac.uk, orcid.org/0000-0003-4449-2281

3 Professor of Integrated Design, School of Art, Design and Architecture, University of Huddersfield, Queensgate, Huddersfield, HD1 3DH, UK, +441484472281, p.tzortzopoulos@hud.ac.uk, orcid.org/0000-0002-8740-6753

4 Professor, Karlsruhe Institute of Technology, Gotthard-Franz-Str. 3, 76131 Karlsruhe, Germany, +4972160842646, shervin.haghsheno@kit.edu, orcid.org/0000-0002-0602-6370

5 The Lean Construction Institute (www.leanconstruction.org) holds a registered trademark on Last Planner ${ }^{\circledR}$ 
design-bid-build (DBB) is still the most commonly used procurement system (Hinton and Hamilton 2015) and it can be argued that it will remain prevalent in many countries for many years.

In social cognitive theory, human psychosocial functioning derives from the causal relationship between psychological factors, behaviors and situational factors which operate as interacting determinants that influence each other bi-directionally (Wood and Bandura 1989). Ankrah et al. (2008) apply the triadic reciprocal relationships to the construction project context and confirmed an association between personal factors, situational contexts and behaviors within the construction project organization. It can be therefore hypothesized that if the internal dispositions of project participants can be determined and the behavior of project participants can be positively influenced, for example, by lean management tools such as the Last Planner ${ }^{\circledR}$ System, the situational context in which project participants operate can be influenced too, meaning a shift to more positive, collaborative environment. To understand the applicability of such bottomup approach, we should understand the environment in which construction is operating. This study aims to describe DBB procurement and to explore its effects on construction projects, environment and project participants through a review of existing literature.

\section{METHOD}

In order to fulfil the research purpose, a literature review was conducted to find evidence of negative effects of the DBB procurement method on construction projects.

Articles with keywords "Design-bid-build" AND ("Behavior" OR "Behaviour") were found using ARCOM and Google Scholar search engines. These articles were sorted by relevance and visually scanned: titles, keywords and abstracts were analyzed. Other articles that were referenced in the initial pool of articles and that were referencing them, were also found potentially relevant. That was a so called 'Snowballing' process (Wohlin 2014). These additional articles were also fully read. As a result, 49 articles were found to be relevant for the research topic. This approach might have caused certain errors as some articles might have been overlooked. Nevertheless, the authors assume that the examined articles reflect the existing effects of DBB on construction industry.

\section{LITERATURE REVIEW}

In this section, the historical development of the DBB procurement are described, and the existing problems in traditional construction environment presented and summarized.

\section{WHAT IS DESIGN-BID-BUILD?}

There are multiple ways to procure buildings (Loosemore 1998). Procurement occurs through an organizational design that determines the line of relationships and communication between project participants among which are clients, contractors and consultants (Dada 2012). No single procurement method is applicable and adaptable to all situations (Rowlinson 1999).

DBB, also called traditional (Rowlinson and McDermott 1999) or "stage-gate" (Lenfle and Loch 2010), is a procurement method that imposes a contractual and organizational separation of design from construction.

DBB is the oldest method of procurement and has been the most dominant in the procurement of building works in many countries (Hinton and Hamilton 2015). It has been the professional standard of project management since the US Project Management 
Institute was created in 1969 (Lenfle and Loch 2010). The adoption of DBB in the construction industry has become a common practice (Ali 2017).

The following description of DBB process from Loosemore (1998) is based on Royal Institution of British Architects (1980). DBB has a similar structure in other countries, with minor differences. DBB is a sequential framework in which the architect plays a central role. It starts with the client commissioning an architect to oversee the production process through design and construction. After clarifying the client's requirements and the feasibility of the scheme, a design team is assembled by the architect. The design process then moves through a number of phases during which the design becomes ever more detailed. Contractors (either main contractor or specialty contractors) are not involved in the design process and are employed once the design has been substantially completed, usually by competitive tender based upon a priced bill of quantities. This is a document which itemizes all the elements of the contractor's work and which all tendering contractors are required to price in order to provide a common basis for their evaluation. On larger projects, this document can run to several volumes. The result of the tendering process is the appointment of a successful contractor, usually on the basis of the lowest price. The client then enters a direct contractual arrangement with the successful main contractor or several specialty contractors, the construction stage commences, and the bill of quantities becomes a binding document against which the contractor is paid. Then, the contractors take responsibility for the production of the building and can subcontract portions of the work. The final stages of this process involve commissioning the building, setting final accounts and providing feedback.

\section{Why do Clients, Architects and Consultants Choose DBB?}

Competitive tendering has traditionally been favored for procuring construction projects, especially in the public sector where it is still considered as the best route for achieving efficiency, transparency and equity, as well as preventing corruption and favoritism (Boukendour and Hughes 2014). The separation of design activities from construction activities involves a strict allocation of responsibilities and risks among the entities performing these activities (ibid.). The 'lowest price wins' mentality remains ingrained because of an industry culture that values tradition and familiarity (Hinton and Hamilton 2015). The industry is guided by consultants and architects who are understandably averse to the risk of reputational damage and hence avoid alternative procurement models (ibid.). Hinton and Hamilton (2015) identify two reasons for consultants and architects to recommend the competitive tendering: first, they remain remote from the submitting and awarding of tenders down the supply chain. Second, if they are aware of questionable conduct, they can choose to ignore this as they are not directly accountable.

Clients remain understandably cost focused even when alternative procurement methods are acknowledged (Wood and Ellis 2005). Even when clients want to establish more cooperative relationships with contractors, the choice of procurement is not always consistent with their wish (Eriksson et al. 2008). There is a difference between desired situation and actual behavior of clients possibly due to earlier experience (ibid.).

Most players accept without question the procurement of construction by competitive tender, viewing it as the cost of doing business (Hinton and Hamilton 2015).

\section{NeGATIVE EFFECTS OF DBB ON CONSTRUCTION ENVIRONMENT}

Although DBB seems to be well suited for small and simple projects, it has proven to be inefficient in more complex projects where cooperation is the key (e.g., Bajari et al. 2009). 
In this section, the direct and indirect effects of DBB on construction environment are showed. First, flow problems are described. These are the direct problems which occur after 'building the walls' between architects and contractors. Second, claims and opportunistic behavior, which are the results of bidding procedures and low margins in the industry, are discussed. Finally, problems related to subcontracting are shown.

\section{Flow Interruptions}

Latham (1994) reported reasons for time and cost overruns in construction projects: traditional procurement is strictly sequential, but increasing urgency from clients has tended to encourage the overlapping of design and construction; abuses of competitive tendering have become common and restrictively-low margins have resulted in a lack of trust within the project team and the emergence of increasingly confrontational relationships.

DBB leads to several generic flow process problems (based on Dupagne 1991):

- There are few or no iterations in the design process. Contractors are not present at the design stage, therefore, they cannot deliver their feedback on constructability and bring their know-how about materials, construction processes, machines and technologies. Interaction between architects and contractors starts too late, when costs of changes are already high.

- Unnecessary constraints for subsequent phases are set in the design phase (poor consideration of requirements of next internal customers). Initial designs are subject to change in almost all projects (Bajari et al. 2009). Once the owner, the architect/engineer, and the contractor need to negotiate for compensating changes, the adversarial nature of DBB coupled with stringent contractual agreements hinders flexible communication and interactive learning among them, leading to inefficiency in handling unforeseen circumstances (Perkins 2009).

- Little feedback for specialists (poor process transparency, segmented project control). According to Dada (2012), the main issue named by construction specialists is 'where sought at all, inputs of contractors are at best advisory'.

- Lack of leadership and responsibility for the total project (segmented project control). When design and construction are separated, there is normally no project leader who is responsible for the whole project delivery.

Consequently, the sequential procedure, resulting from DBB, leads to (Koskela 1992):

- Suboptimal solutions. When some information is missing during the decisionmaking process, the decisions made during the design stage may be suboptimal.

- Poor constructability and operability. The architects cannot take into consideration all the construction methods which different contractors might use. Lack of experience of working on construction site can also play negative role in the design solutions.

- Large number of change orders (and thus rework in design and construction). If design has mistakes and shortcomings or if design solutions did not take into account the conditions on construction site or on market, the changes in design are needed. It may lead to a change in construction, depends on the point of time when a mistake or inconsistency occurred: if it was before execution on a construction site or before producing the prefabricated parts, it may lead "just" to design changes, otherwise, it will often lead to physical changes in construction. 
- Lack of innovation and improvement. If designers and contractors are not continuously exchanging the ideas, experience and know-how, it leads to 'I have been doing it my whole life this way' mentality, when neither designers nor contractors are interested in impoving their procedures, processeses, standard solutions.

Sacks and Harel (2006) describe the adversarial nature of the relationship regarding resource allocation, showing that lack of faith between project managers and subcontractors is an expected result of the conditions created by traditional unit price or lump sum contractual arrangements, particularly when work plans are unreliable. His model explains how sub-optimal conditions can be stable, how local optimization works against flow, and how unit price contracting hides the waste of sub-optimal productivity within the price paid per unit of work completed.

Sarhan et al. (2018) introduce the concept of 'institutional waste' within the construction procurement context, which emphasizes the significance of how imperfect regulations, norms, cultural and cognitive assumptions may influence approaches to construction procurement, leading to irreconcilable and self-perpetuating cycles of waste which can be here in the form of monetary, time, effort or value loss, and can occur prior to or post contractual stages.

\section{Claiming Culture and Opportunism}

There may be conflicts between project participants: between clients and contractors, designers and contractors, contractors and subcontractors and so on. Conflict within the construction process is as prevalent today as it was at the time of the Simon Report (1944). Instead of collaborating and taking collective responsibility for achieving the best outcomes for the project, the parties tend to seek to maximize their own interests, and to transfer risks to their contractual counterparts, which actions inevitably result in endemic claims and disputes (Boukendour and Hughes 2014). Transaction cost economics (TCE) predicts that opportunistic behavior is negatively related to the performance of a cooperative relationship (Lui et al. 2009). Aibinu et al. (2011) suggest that perceptions about organizational justice either promote or hinder cooperative behavior in the construction project delivery process. It is not enough simply to design formal contract processes and procedures when attempting to minimize claims and reduce conflict and dispute.

The culture of the construction industry in Germany has been described as a "culture of claims" (Schöttle and Gehbauer 2013). The DBB, the lack of knowledge as well as the project experience of the stakeholders in general, especially in context of profit maximization, sets negative incentives which leads to uncooperative behavior and noncollaboration. Moreover, the disincentives establish an inflexible framework, where uncoordinated dependency between the parties occurs.

Rooke et al. (2004) outline the economic origins of the claims culture. An important element in the contractor's approach is the planning for claims at tender stage: one of methods is concerned with pricing the bill of quantities. The art of contractor's work is in spotting mistakes which can then be exploited. Another method of designing claims centers on the programme for the work. Programmes are designed in order to anticipate and maximize the cost of delays, for which the client will be liable. Organizational conditions are also important reasons for claims. A procurement system that emphasizes tender price as the sole or principal criterion of selection creates the conditions in which contractors are encouraged to plan for claims from the very inception of a project; a 
situation exacerbated in periods of economic recession in which 'buying work' by underbidding at tender stage may be commonplace. Mohamed et al. (2011) found that contractors might reduce their bid profits deliberately to secure the projects and then seek profits from claims subsequently, capitalizing on potential claims recovery or mismanagement by the owners.

The competitive tender, played out in an environment of intense competition in which multiple competitors can only secure access to the market via a few larger and more powerful organizations, contributes to the industry's inefficiency and poor profitability (Hinton and Hamilton 2015). It does this by requiring actors, both the powerful and disempowered to relax their moral constraints when confronting market forces.

Hinton and Hamilton (2015) illustrate that opportunism is a driving factor of convenient immorality. Convenient immorality is at the center of the model, both a consequence and a contributor to the environmental-cultural context of the industry. Convenient immorality is built upon the three high-level constructs: opportunism, control and power.

Consistent with Wathne and Heide's view (2000) who reviewed the conceptualizations of opportunism and explained them through case analyses, during which they discussed two general categories of opportunistic behavior: passive and active, opportunistic behaviors are categorized by Hinton and Hamilton (2015) as either proactive or reactive. Proactive behaviors are pre-tender and intended to make the bid as attractive as possible, i.e. lowest cost, but also sufficiently profitable. These typically involve a degree of intended ambiguity: bid obfuscation, bid gambling and playing the grey. Reactive behaviors are those used once tenders have been submitted, intended to increase the chances of securing the job but often requiring breaches of confidence: price shopping, post-tender negotiating, mirrored immorality, when the participants replicate the unethical behaviour of others.

Loosemore and Lam (2004) researched impediments and drivers of opportunistic behavior in construction. They group the main impediments to opportunism under two headings: manmade and institutional. Manmade impediments are those created by the construction industry's managerial practices which lead to culture of confrontation, mistrust and individualism, resulting in an environment of mediocrity with little incentive to seek opportunities to improve performance; the myriad of complex, legalistic and voluminous contracts, which distribute risks ambiguously and inequitably in construction projects. Institutional impediments to opportunism are those that are created by external institutional bodies or which are embedded in the industry's culture as a result of its historical development.

Loosemore and Lam (2004) call the construction industry's hierarchical, classbased structure that has resulted in a construction process that is divided along functional lines, particularly design and construction, an intra-institutional impediment. The self-imposed isolationism of construction professions has produced an industry that is characterized by a diverse range of languages, cultures, aspirations, needs and interests. This is unconducive to the effective communication, teamwork, and sense of trust and collective responsibility that is needed for a positive environment that is conducive to opportunistic behaviour. Five main factors that can drive opportunistic behavior in the construction industry identified by Loosemore and Lam (2004) are locus of control, luck, capital, attitudes, flexibility.

Pryke and Smyth (2006) explain that there is a common conflict between the client and the contractor regarding the long-term objectives versus the short-term, in the same 
way their perception of efficiency and effectiveness is rather different. In terms of dealing with cost, there is always the pressure to produce profit using either short- or long-term strategies: where the client needs a high value for his project, the contractor is looking for a reasonable profit (Boyd and Chinyio 2008).

Among previous studies on opportunistic behavior, some have focused specifically on Public Private partnership (PPP) contracts. Due to the extreme complexity of PPP contracts, opportunistic behavior is a crucial issue and plays an important role for the collaboration (Hu et al. 2015). The existence of opportunism might lead to more conflicts and weaken the foundation for collaboration (Luo 2007). In PPP projects, the goals of the government and the private investors are different: the goal of the government is to maximize social benefits, whereas the goal of the investors is to maximize their own profits, therefore, investors universally have the tendency of embracing an opportunistic behaviour (Liu et al. 2017).

\section{Subcontracting}

The importance and extent of subcontracting is familiar to all involved in construction. Its prevalence has been documented in numerous studies (Edwards 2003). Wilkinson et al. (2012) portray the industry's workforce as 'largely fragmented, transient and heterogeneous' and its subcontracting base as 'problematic'. These are concomitants of competitive tendering with each subcontractor compelled to work within the delimited scope of their respective tenders and none with any responsibility for the quality delivered to the client (Håkansson and Ingemansson 2013).

With the growth of subcontracting have come fragmentation, instability, shorttermism, reduced customer orientation and problems of communication, coordination, motivation and quality control. These problems have had the effect of focusing peoples' mind on avoiding the potentially adverse effect of risk rather than maximizing its potential benefits (Loosemore and Lam 2004).

Packham et al. (2001) indicate that power relationships serve as a potential barrier to the successful adoption of the partnering philosophy. It is concluded that subcontractors, under existing partnering arrangements, are vulnerable to bullying by main contractors.

\section{FINDINGS}

To conclude, the direct and indirect negative effects of DBB on the construction environment have been found. They are summarized in the form of a tree diagram (Figure 1).

The effects presented in this diagram are overlapping and because of their feedback loops are both consequences and contributors to the construction environment. However, the negative effects of DBB approach on the construction industry can still be grouped and lead to two main problems: flow interruptions and low margins in the industry.

Main flow interruptions include the fragmentation of the industry (design and build phases are separated), poor constructability (construction companies are not involved in design process), lack of responsibility for the total project (there are no managers who are controlling the whole life cycle of the construction process), hindrance of learning (knowledge stays in the silos), which lead to several consequential problems, such as short-term goals (project participants are forced to think about short-term profits rather than long-term strategies), an increasing number of change orders (designers either issue the drawings that are subject to change because the contractors were not involved in the design process or do not produce the drawings with good enough level of details because 


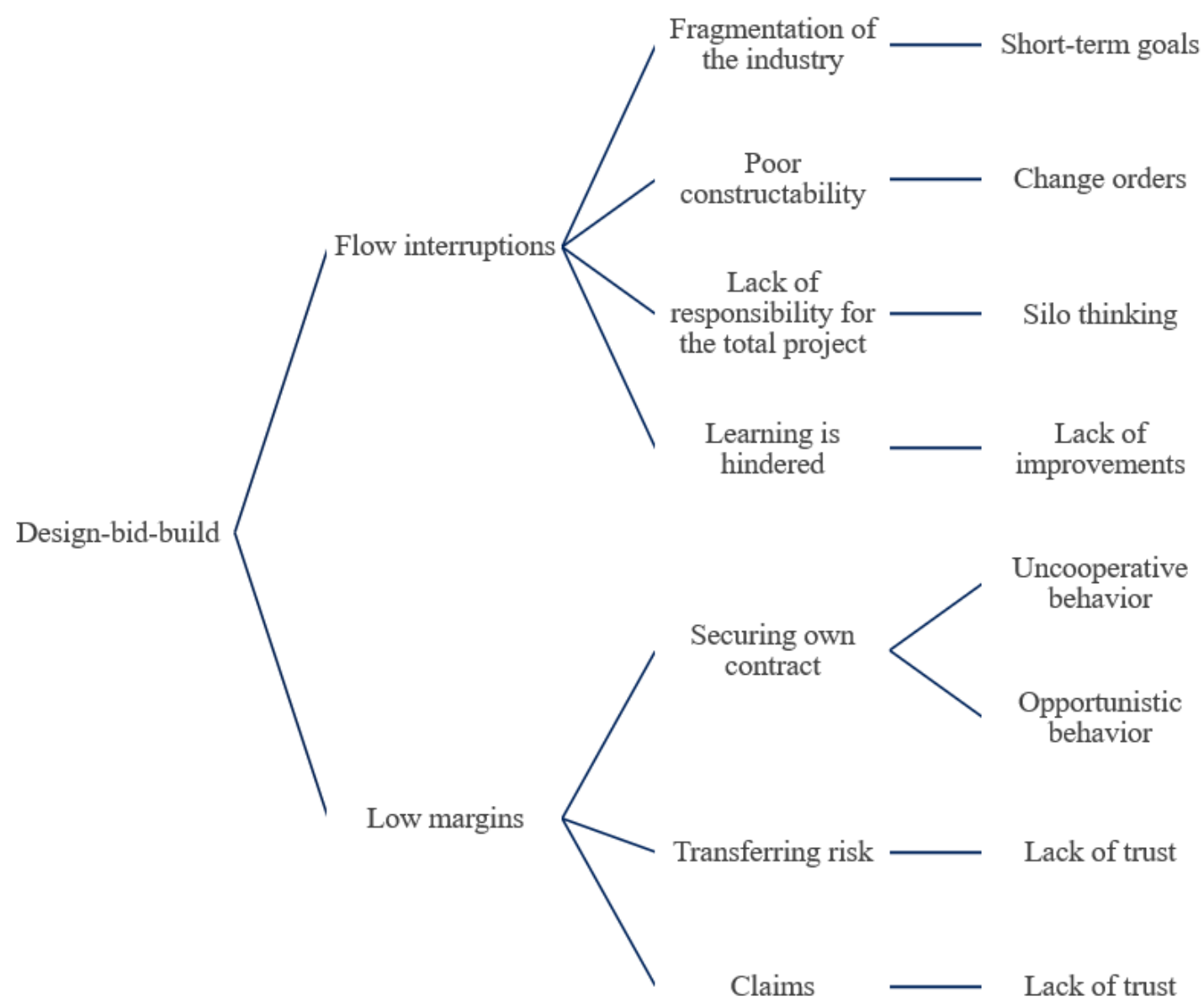

Figure 1: Negative Impacts of Design-Bid-Build Procurement Method on Construction Environment in a Form of a Tree Diagram

designers know that contractors would probably want to change them, which leads to request for information and change orders), silo thinking (each party is optimizing its own part, ignoring the whole picture), lack of improvements and innovation (improvements take into account the needs of sub-processes, not the whole project).

Low margins lead to the situation that companies are forced to secure their contracts and own interests and transfer their risks which encourages uncooperative and opportunistic behavior (for example, when the companies try to use their knowledge of the shortcomings in the construction documents or conditions on site to make more profit). This claim culture leads to lack of trust and toxic environment, well known in construction world.

\section{DISCUSSION}

The state of things in the DBB construction environment could remind of the Prisoner's Dilemma, a paradox described in modern game theory, in which two individuals acting in their own self-interest do not produce the optimal outcome. In the typical prisoner's dilemma situation, both parties choose to protect their own interest at the expense of the other participant. As the result, both participants find themselves in a worse state than if they had cooperated with each other in the decision-making process (Powers 2019). Similarly, the decisions of participants in the construction industry are often driven by self-interest and not by a comprehensive success of a project in the eyes of the ultimate 
customer. One of the reasons for these unwritten rules in construction, 'the strongest wins' and 'if you don't beat them, they will beat you', is DBB. It is a traditional procurement method that leads to high walls between the participants, encouraging silo-thinking. It is the competitive tendering, resulting in low margins, making parties feel uncomfortable even to think about other things than securing their contracts and optimizing their own workflows.

The possible solutions to overcome the shortcomings of traditional procurement through integrated forms of contract have been widely discussed. Naoum (2003) advances partnering on the UK construction projects. Heidemann and Gehbauer (2010) discuss multi-party agreements, integrated form of agreement in the USA and alliancing agreement in Australia, and suggest the adjustment of the existing DBB procedure in Germany. However, sometimes it is not possible to use other forms of procurement than DBB: there are legal, cultural, behavioural, technological and financial barriers against implementing integrated project delivery (Dargham et al. 2019).

It must also be mentioned that DBB has been seen as a constraint to the implementation of lean construction. dos Santos and Tokede (2016) argue even that LPS may not be applicable to DBB. Fuemana et al. (2013) state that there is little exploration of the effect that the choice of procurement method has on the use of LPS, but that it became obvious for them during interviews with site and project managers working for main contractors in New Zealand that the chosen procurement method had a significant impact on achieving a trouble-free and successful implementation of LPS.

We contend that the effects of DBB described in this paper prevent collaboration, which is a prerequisite for lean construction. DBB leads to silo thinking which derives from the way the contract structure is built. For DBB, it is normal that the parties that start working together have not had the relationships before. In DBB, a lot of time should be spent firstly to create communication structures. Normally, there is no time for it as the processes on construction site should progress. Without communication channels between them, the parties find themselves in the prisoner's dilemma situation, when they are separated and try to protect their own interest instead of collaborating.

The question arises, how can we encourage the parties to cooperate and how do we stimulate open communication under the negative effects of DBB? What if we make it without switching to multi-party contractual arrangements: if we admit that DBB will stay in the construction industry for the foreseeable future, could we change the behavior of construction project participants with lean management tools without using procurement methods like integrated project delivery? Would that influence the industry environment? It can be hypothesized that if the internal dispositions of project participants can be determined and the behavior of project participants can be positively influenced, for example, by the Last Planner ${ }^{\circledR}$ System, the situational context in which project participants operate can be influenced too, meaning a shift to a more positive, collaborative environment. This hypothesis is a part of an ongoing $\mathrm{PhD}$ research.

\section{CONCLUSIONS}

The DBB approach was historically invented because of the situation when a client wanted to invest his or her money in a construction project and approached a master builder who normally was an architect to solve this issue. An architect then designed a building and, as a client usually did not have enough experience and expertise in the construction world, helped him or her to find a contractor to realize the proposed design. The quantity surveyor who appeared in the UK construction industry in the 17th century 
or the architect prepared a bill of quantities and then compared the contractors ' proposals based on this bill to make the choosing process as transparent as possible. The competitive tendering process provided the client the cheapest proposal to realize the same building, therefore it was the best proposal for the client, and the tendering process was transparent, logical and easy to follow.

The DBB has been also recently reinforced by Project Management Institute. The legislation in many countries require a DBB process as a countermeasure to corruption. The DBB is dominating the construction industry all over the world. Its long history, convenience of choosing the cheapest price and reluctance of the construction project participants to accept the new ways of doing business collaboratively, to open cards and to share information with the companies involved in the project procurement (architects, engineers, quantity surveyors, consultants, contractors, subcontractors, clients) in order to reach the common project goal, to minimize waste and to become more productive and efficient, leads us to the important conclusion that the traditional procurement method will still be prevalent in the construction world in the foreseeable future.

Up to now, the constraints created by DBB for the implementation of lean construction, especially LPS, have been examined and discussed. The practical question arises: how can LPS help to fix the DBB problems, even if the potential of LPS will not be fully unleashed?

\section{REFERENCES}

Aibinu, A. A., F. Y. Y. Ling, and G. Ofori. 2011. "Structural equation modelling of organizational justice and cooperative behaviour in the construction project claims process: contractors' perspectives." Construction Management and Economics, 29 (5), 463-481.

Ali, A. K. 2017. "Architecture within a circular economy: Process mapping a resourcebased designbid-build project delivery system." Enquiry The ARCC Journal for Architectural Research, 14 (1), 48-61. https://doi.org/10.17831/enq:arcc.v14i1.432.

Ankrah, N. A., D. G. Proverbs, and D. K. Ahadzie. 2008. "Exploring the behaviours of construction project participants through social cognitive theory." In Proc., 24th Annual ARCOM Conf., edited by A. Dainty, 443-453. Cardiff, UK: Association of Researchers in Construction Management.

Bajari, P., R. McMillan, and S. Tadelis. 2009. "Auctions versus negotiations in procurement: an empirical analysis." J. Law Econ. Org., 25 (2), 372-399.

Boukendour, S., and W. Hughes. 2014. "Collaborative incentive contracts: stimulating competitive behaviour without competition." Construction Management and Economics, 32 (3), 279-289.

Boyd, D., and E. Chinyio. 2008. Understanding the construction client. Oxford, UK: Blackwell Publishing.

Dada M. O. 2012. "A second look: Stakeholders' perceptions of some issues in designbid-build procurement practice in Nigeria." Journal of Sustainable Development, 5 (1), 55-64. http://dx.doi.org/10.5539/jsd.v5n1p55.

Dargham, S. A., M. BouHatoum, M. Tohme, and F. Hamzeh. 2019. "Implementation of IntegratedProject Delivery in Lebanon: Overcoming the Challenges." In: Proc., 27th Conf. of the Intern. Group for Lean Constr., 917-928. Dublin, Ireland: International Group for Lean Construction.

Dos Santos, G. F. and O. O. Tokede. 2016. "Last Planner System-from theory to implementation." In Proc. of the 10th Cost Engineering, Quantity Surveying \& Project 
Management World Congress, 305-318. Rio De Janeiro, Brazil: International Cost Engineering Council.

Dupagne, A. 1991. "Computer Integrated Building. Strategic Final Report." ESPRIT II: Exploratory Action, 5604, 24-28.

Edwards, D. J. 2003. "Accident trends involving construction plant: an exploratory analysis." Journal of Construction Research, 4 (02), 161-173.

Eriksson, P. E., T. Nilsson, and B. Atkin. 2008. "Client perceptions of barriers to partnering." Eng. Construct. Architect. Manage., 15 (6), 527-539.

Fuemana, J., T. Puolitaival, and K. Davies. 2013. "Last Planner System - a step towards improving the productivity of New Zealand Construction." In Proc., 21st Conf. of the Intern. Group for Lean Constr., 679-688. Fortaleza, Brazil: International Group for Lean Construction.

Håkansson, H., and M. Ingemansson. 2013. "Industrial renewal within the construction network." Construction Management and Economics, 31 (1), 40-61.

Hamzeh, F., F. Rached, Y. Hraoui, A. Karam, Z. Malaeb, M. El Asmar, and Y.Abbas. 2019. "Integrated project delivery as an enabler for collaboration: a Middle East perspective." Built Environment Project and Asset Management, 9 (3), 334-347. https://doi.org/10.1108/BEPAM-05-2018-0084.

Heidemann, A., and F. Gehbauer. 2010. "Cooperative Project Delivery in an Environment of Strict Design-Bid-Build Tender Regulations." In Proc., 18th Conf. of the Intern. Group for Lean Constr., 581-587. Haifa, Israel: International Group for Lean Construction.

Hinton, M. A., and R. T. Hamilton. 2015. "Competitive tendering and individual behaviour in the construction industry: convenient immorality at work." Construction Management and Economics, 33 (11-12), 880-889.

Hu, B., A. Leopold, and S. Pickl. 2015. "Concept and prototype of a web tool for publicprivate project contracting based on a system dynamics model." Cent. Eur. J. Oper. Res., 23 (2), 407-419.

Koskela, L. 1992. "Application of the new production philosophy to construction." CIFE Technical Report 72. Stanford, USA: Stanford University.

Latham, M. 1994. Constructing the team: final report on joint review of procurement and contractual agreements in the UK construction industry. London, UK: Her Majesty's Stationery Office.

Lenfle, S., and C. Loch. 2010. "Lost roots: How project management came to emphasize control over flexibility and novelty." Calif. Manage. Rev., 53 (1), 32-55.

Liu, J., R. Gao, C. Y. J. Cheah, and J. Luo. 2017. "Evolutionary game of investors' opportunistic behaviour during the operational period in PPP projects." Construction Management and Economics, 35 (3), 137-153.

Loosemore, M. 1998. "The three ironies of crisis management in construction projects." Int. J. Proj. Manag., 16 (3), 139-144.

Loosemore, M., and A.S.Y. Lam. 2004. "The locus of control: a determinant of opportunistic behaviour in construction health and safety." Construction management and economics, 22 (4), 385-394.

Lui, S.S., Y.Y. Wong, and W. Liu. 2009. "Asset specificity roles in interfirm cooperation: reducing opportunistic behavior or increasing cooperative behavior?” J. Bus. Res., 62 (11), 1214-1219.

Luo, Y. 2007. “An integrated anti-opportunism system in international exchange.” J. Int. Bus. Stud., 38 (6), 855-877. 
Mahamid, I. 2016. "Factors contributing to poor performance in construction projects: studies of Saudi Arabia." Australian Journal of Multi-Disciplinary Engineering, 12 (1), 27-38. http://dx.doi.org/10.1080/14488388.2016.1243034

Miller, C. J., G. A. Packham, and B. C. Thomas. 2001. Harmonisation and lean construction: acknowledging the role of the small subcontracting firm. Pontypridd, Wales: Welsh Enterprise Institute.

Mohamed, K. A., S. S. Khoury, and S. M. Hafez. 2011. "Contractor's decision for bid profit reduction within opportunistic bidding behavior of claims recovery." Int. J. Proj. Manag., 29 (1), 93-107.

Packham, G. A., B. C. Thomas, and C. J. Miller. 2001. Partnering in the Welsh construction industry: a subcontracting perspective. Pontypridd, Wales: Welsh Enterprise Institute.

Perkins, R. A. 2009. "Sources of changes in design-build contracts for a governmental owner." J. Constr. Eng. M., 135 (7), 588-593.

Powers, R. 2019. Prisoner's dilemma. London, UK:Atlantic Books.

Pryke, S., and H. Smyth. 2006. The management of complex projects: a relationship approach. Oxford, UK: Blackwell Publishing.

Rooke, J., D. Seymour, and R. Fellows. 2004. "Planning for claims: an ethnography of industry culture." Construction Management and Economics, 22 (6), 655-662.

Rowlinson, S., and P. McDermott. 1999. Procurement systems: A guide to best practice in construction. London, UK: E \& FN Spon Ltd.

Royal Institution of British Architects. 1980. RIBA Handbook of Architectural Practice and Management. London, UK: RIBA Publications.

Sacks R., and M. Harel. 2006. "An economic game theory model of subcontractor resource allocation behaviour." Construction Management and Economics, 24 (8), 869-881.

Sarhan, S., C. Pasquire, A. King, and E. Manu. 2018. "Institutional waste within the UK construction procurement context: A conceptual framework." Engineering Project Organization Journal, 8, 36-64.

Schöttle, A., and F. Gehbauer. 2013. "Incentive structure in public design-bid-build tendering and its effects on projects." In Proc., 21th Conf. of the Intern. Group for Lean Constr., 227-236.Fortaleza, Brazil: International Group for Lean Construction.

Simon, S. E. 1944. The placing and management of building contracts: report of the Central Council for Works and Buildings. London, UK: Her Majesty's Stationery Office.

Wathne, K. H., and J. B. Heide. 2000. "Opportunism in interfirm relationships: forms, outcomes, and solutions.” J. Marketing, 64 (4), 36-51.

Wilkinson, A., S. Johnstone, and K. Townsend. 2012. "Changing patterns of human resource management in construction." Construction Management and Economics, 30 (7), 507-512.

Wohlin, C. 2014. "Guidelines for snowballing in systematic literature studies and a replication in software engineering". In Proc., 18th International Conference on Evaluation and Assessment in Software Engineering, 1-10. London, UK: ACM.

Wood, G., and R. C. Ellis. 2005. "Main contractor experiences of partnering relationships on UK construction projects." Construction Management and Economics, 23 (3), 317 325.

Wood, R., and A. Bandura. 1989. "Social cognitive theory of organizational management." Acad. Manage. Rev., 14 (3), 361-384. 